\title{
El «discurso del Amo» en una epístola poética de César Moro ${ }^{1}$
}

\section{The «speech of the Master» in a poetic epistle of César Moro}

\author{
Jhonny Jhoset Pacheco Quispe ${ }^{2}$
}

Universidad Nacional Mayor de San Marcos, Lima, Perú

jhonnypachecoquispe@gmail.com

\section{RESUMEN}

En el presente artículo se aborda el análisis de una epístola poética que corresponde a las Cartas a Antonio, de César Moro. Así, se describe la categoría del «discurso del Amo», el cual funciona como mecanismo poético de índole amoroso en el que participan dos actuantes, el Amo y el Esclavo, además de delinear las consecuencias de este procedimiento. Para realizar ello, utilizamos el marco teórico psicoanalítico de Jacques Lacan vertido en sus Seminarios. Y la herramienta de trabajo textual que usamos es la hermenéutica.

\section{PALABRAS CLAVE}

Epístola, «discurso del Amo», el Amo y el Esclavo, psicoanálisis

\section{ABSTRACT}

This article is about the analysis of an poetic epistle, who belongs to the Cartas a Antonio, of Cesar Moro. So, it's describes the chategory of «speech of the Master», that can operate like poetic mechanism of love style, where participe two characters, the Master and the Slave, besides describes the consequences of this procedure.

\footnotetext{
1 Este artículo es parte del segundo y tercer capítulo de mi tesis de maestría en Literatura Peruana y Latinoamericana titulada El discurso del Amo en las Cartas a Antonio de César Moro, presentada en la Universidad Nacional Mayor de San Marcos.

2 Jhonny Jhoset Pacheco Quispe es licenciado en Literatura por la Universidad Nacional Mayor de San Marcos. Concluyó estudios de maestría y doctorado en Literatura Peruana y Latinoamericana en la misma casa de estudios. Ha publicado artículos y reseñas de libros en diario Exitosa y revistas como Lucerna, Desde el Sur, Ínsula Barataria; en los sitios web Lee por Gusto, Iluminaciones. Literatura Fantástica y Ciencia Ficción, El Hablador y Letras s5 de Chile. También ha participado en diferentes congresos y coloquios sobre literatura fantástica, poesía peruana y estudios de género. Codirige, además, la editorial independiente Agalma. En 2014, publicó su primer poemario, Anatomía de la tierra, de estilo neobarroso.
} 
Consequently, we use Jacques Lacan's theoretical and psychoanalytic framework in his seminars. And the textual work tool we use is hermeneutics.

\section{KEYWORDS}

Epistle, «speech of Master», the Master and the Slave, psychoanalysis

\section{Introducción}

César Moro es uno de los vates importantes de nuestra tradición lírica peruana; sin embargo, su poesía no ha tenido la recepción crítica adecuada por varias décadas, sino recién en los años del nuevo milenio. Tal vez, este desdén exegético tenga algunas razones, verbigracia, el idioma francés, el lenguaje surrealista y el tópico de amor uranista. En primer lugar, la lengua francesa, en la que se encuentra casi la totalidad de su obra, es un impedimento para apreciar su riqueza lírica pese a las traducciones que existen actualmente, allende de direccionar solo la lectura del único poemario hecho en español, La tortuga ecuestre, relegando de este modo el resto de su producción a la indiferencia; en segundo lugar, las imágenes surrealistas, además de la escritura automática como técnica de creación, imposibilitan el aprecio inmediato para los lectores nuevos, pues sus metáforas transgresoras, unión de contarios, generan una ruptura en el logos tradicional; por último, el tema de la homosexualidad ha principiado no solo el sesgo y censura de sus escritos, sino el asunto preferido de investigadores que, con una mirada biografista, han eclipsado otras perspectivas analíticas.

Con esta tradición impuesta, aunque superada en las últimas aproximaciones, el presente artículo es divergente en cuanto al objeto de estudio y la cuestión tratada, pues hemos focalizado nuestra hermenéutica en las Cartas a Antonio, un conjunto de poemas escasamente examinado, o analizado tangencialmente ex profeso de libros publicados; del mismo modo, en el enfoque propuesto se ha tratado de ingresar al mismo funcionamiento poético que permite el desarrollo de una disertación amorosa, como es el «discurso del Amo». Para realizar dicho cometido, se ha utilizado el marco teórico del psicoanálisis de Jacques Lacan enunciado in extenso en su obra, específicamente, el Seminario 17. El reverso del psicoanálisis.

Por lo expuesto, lo que se pretende demostrar es la relación de subordinación que existe entre los interlocutores de una epístola correspondiente a las Cartas a Antonio. Con este engranaje lírico, se despliega la interacción de un Amo, emisor, amado, y un Esclavo, receptor, amante, con el objetivo de mantener el dominio y el amor; empero, esta estructura no 
se halla en cordialidad perenne, sino en zozobra continua, dado que hay circunstancias que inhiben el éxito de este decurso a perpetuidad, por lo que se vuelve imposible de sostener, e incluso, de realizar.

\section{El «discurso del Amo»}

El sistema de subordinación, el «discurso del Amo» que se desprende de las Cartas a Antonio, tiene correlación con el proceso de significación del sujeto, es decir, con el mecanismo de castración del individuo que le permite ingresar al mundo de lo Simbólico. Así, dichos dispositivos servirán como ejes constituyentes del amor en la circular moreana, por ejemplo, la cadena significante, donde se produce la relación fundamental entre un significante con otro $\left(\mathrm{S}_{1}\right.$ y $\left.\mathrm{S}_{2}\right)$; el significante, que tiene una lógica de representar a un sujeto para otro significante; el significante $\operatorname{Amo}\left(\mathrm{S}_{1}\right)$, Fundante, que inicia el desplazamiento significacional comportando a un sujeto hacia otro significante; el Esclavo $\left(\mathrm{S}_{2}\right)$, quien tiene la función de hacer y sustentar el sometimiento para que el sujeto se convierta en Amo; el sujeto (S), quien es representado por un $S_{1}$ ante un $S_{2}$ con la finalidad de ser castrado; el sujeto barrado (\$), que es el resto dejado luego del proceso de desubjetivación; y el objet petit a, elemento primordial perdido del $\mathrm{S}$ para convertirse en $\$$. Además de estas partes constitutivas, existen sitios de significación en el cual se realiza esta estructuración, verbigracia, el Otro, lugar de inscripción donde se sitúan los objetos imaginarios, el Esclavo y el saber que este prodiga con su trabajo, allende de efectuarse aquí la irradiación que fascina y motiva al $\mathrm{S}_{1}$ a trasladarse; el «más allá» del espejo, espacio donde se produce las identificaciones por parte del sujeto debido a la concatenación y puesta en ejecución de la teoría del espejo que posibilita la emergencia y conversión de aquel en \$; el plano Imaginario, emplazamiento en el que se localizan los objetos imaginarios, además de concebirse una vida utópica donde lo imposible se vuelve plausible; lo simbólico, el referente donde gobiernan los símbolos, el lenguaje, la palabra, en el que el sujeto se posiciona como tachado, \$, pues ha perdido algo que era en él más que él mismo, el objet petit a; y el ámbito de lo real, el caos primigenio del cual surge el sujeto sin castrar y elementos tales como el amor, la muerte, el sexo, entre otros, que serán discriminados; no obstante, estos permanecerán latentes en la red lingüística, la realidad, ya que son esenciales para la conformación de lo imaginario y lo simbólico.

A partir de lo dicho, lo que se establece es el «discurso del Amo», en el cual el significante Amo empieza su recorrido y proceso de significación hacia $\mathrm{S}_{2}$, gracias a la luminosidad de los objetos identificatorios que fascinan y cautivan al sujeto que se encuentra representado por $S_{1}$. Con este desplazamiento fundacional donde se genera una correspondencia sine qua non entre $S_{1}$ y $S_{2}$, el sujeto no escindido principia su proceso de 
estructuración a través de la teoría del espejo; aquí el $\mathrm{S}$ encuentra y discrimina elementos constitutivos que provienen del Imaginario. En este desarrollo significacional, al S se le transfiere el instinto de muerte, lo real, que lo escindirá de su vivencia imaginaria, por lo que se le desprenderá algo, el objeto-causa de deseo, lo que no que se puede asir. Con esta pérdida, el sujeto es barrado de la imaginación en el que pretendió vivir a perpetuidad. En consecuencia de ello, el S es clivado en \$, allende de ser expulsado a la dictadura de los símbolos, del lenguaje que representa lo ausente y que nunca será encontrado, pues perennemente es desviado por la palabra.

Con este procedimiento, las relaciones de poder entre el Amo y el Esclavo se condicen con el mismo sistema, pues el $\mathrm{S}_{2}$ es el Esclavo, quien trabaja e ilusiona al sujeto no tachado, pues aquel contiene la sabiduría, el saber, que permitirá la concreción para que el S sea un Amo. Con esta ilusión, el sujeto será representado por un significante para asir al Esclavo situado en el Otro, entidad mayor que se encuentra constituido por un tesoro o batería de significantes que dividirán al Amo en uno verdadero, $\$$. Sin embargo, en esta sistematización, el instinto de muerte transferido ocasiona en el Amo una zozobra de su estructura, dado que la muerte causaría la aniquilación del mecanismo subordinante si es que el Esclavo fallece porque todo empezaría de nuevo, mientras que con el fenecimiento del Amo no se espera nada. De esta forma, el «discurso del Amo» está continuamente en desequilibrio por lo que se vuelve imposible de concretar no solo por la destrucción del mundo dominante, sino porque la muerte pertenece al ámbito de lo real, es decir, a lo imposible de ejecutarse.

De lo conjeturado, se desprende una serie de consecuencias que permiten el ejercicio de este orbe relacional de poderes, por ejemplo, el Amo no sabe que es un Amo, pues no tiene el conocimiento para posicionarse tal cual, sino que el Esclavo es quien trabaja para situarlo como \$, aunque esta inhibición no determina que el sujeto desubjetivado no desee serlo; también, hallamos la puesta en escena de la teoría del espejo donde el Amo busca y se asemeja con el Esclavo, por lo que se traslada ilusionado hacia él, ya que este contiene el saber que lo hará un \$; de este proceso, el Amo roba la verdad desprendida del saber del Esclavo para situarse como alguien supremo; empero, el sujeto dividido al apoderarse de la verdad, que pertenece al plano de lo real, se encuentra en relación directa y no concordante con lo imposible, lo que ha sido perdido, porque no hay fantasme que impida esa correspondencia; no obstante, ante ello, el Amo es premunido de dicho acontecimiento, por tanto, se muestra ciego; así, el Amo se ilusiona, ya que vive una utopía donde él y lo que pierde pueden posicionarse en un mismo espacio; sin embargo, esta correlación no logra 
consolidarse, pues será castrado por la muerte; de este modo, debido a este instinto mortal que lo expulsa de ese mundo idílico y asola su plano simbólico, el Amo arriesga todo al intentar relacionarse con el Esclavo. Con lo dicho, podemos diseñar el siguiente esquema:

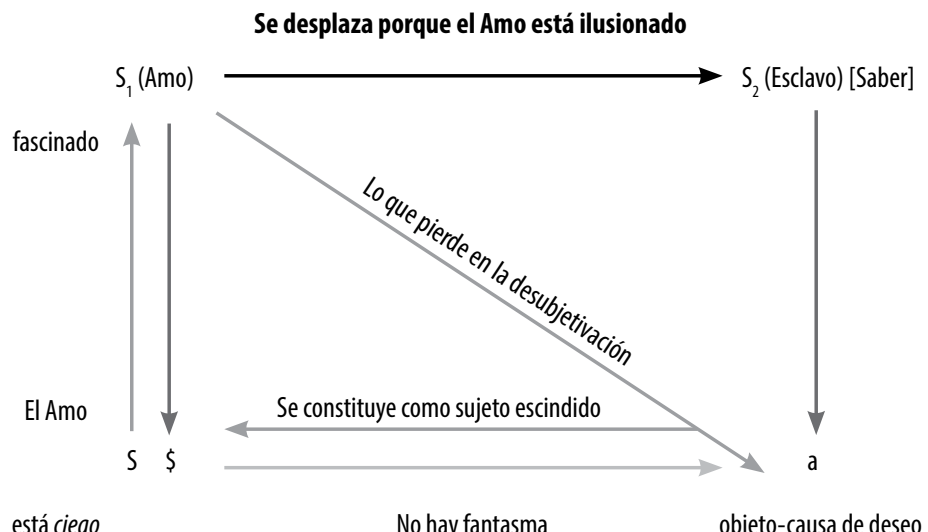

(se relaciona con lo real aunque el $a$ está perdido por siempre)

El sistema es real

En consecuencia de lo disertado, hemos notado que el «discurso del Amo» se imbrica como funcionamiento poético en los poemas en prosa de las Cartas a Antonio (1938-1939), de César Moro, proyecto lírico que pertenece al llamado «ciclo de Antonio» y que escribió durante su estancia en México (1938-1948). En el siguiente apartado, analizaremos el primer texto que inaugura dicho conjunto con la finalidad de demostrar y hacer explícito lo sustentado.

\section{3. «l: Domingo, 23 de octubre [de 1938] $»^{3}$}

Antes de analizar el texto, relacionamos el Amo y el Esclavo con sus respectivos pares del amado, erómenos, y el amante, erastés, es decir, el emisor y el receptor respectivamente ${ }^{4}$. Esta correlación se debe a las características de enunciación que se muestran en el discurso amatorio, en el cual existe una prédica poética que pertenece a la de un erómenos, dado que este responde a la incitación del erastés con lo que se crea el amor. Y ¿por qué afirmamos que es un amado y no un amante? Lo que sucede es que solo el erómenos es capaz de dar su vida por el erastés, destruir el

3 Hemos tomado la fecha consignada en las Cartas a Antonio como referencia para distinguirlas, ya que no llevan título alguno salvo una enumeración en romanos.

4 Este aspecto fue desarrollado en mi investigación anterior, la tesis de licenciatura La metáfora del amor en La tortuga ecuestre de César Moro, sustentada en 2014 en la Universidad Nacional Mayor de San Marcos. 
mundo, transgredir la historia y generar un nuevo referente donde ambos puedan escribir un nuevo orden. Asimismo, luego de la relación de ellos, la implicancia que se gestará es una unión jamás vista. Por este motivo y debido a que estas particularidades se despliegan en otros textos de César Moro, aseveramos que la lógica de enunciación de un erómenos a un erastés se replica, también, en los poemas denominados Cartas a Antonio.

Luego de esta breve explicación sobre los interlocutores, primero, transcribiremos el texto poético completo para que el lector conozca lo que se analizará y pueda comprender mejor el trabajo interpretativo. Luego, se realizará la respectiva exégesis con el método hermenéutico y el psicoanálisis lacaniano explicado. Por último, se efectuará el esquema del «discurso del Amo» que subyace en el escrito «l: Domingo, 23 de octubre [de 1938]».

\section{A. El texto}

La primera epístola que analizaremos corresponde a la edición Obra poética completa, de César Moro, publicado en 2016:

Un deseo de verdadera comunicación contigo se hace más y más urgente. A veces me parece que no somos bastante amigos, que tienes todavía muchas reservas conmigo. Quizá yo, sin quererlo, tengo la culpa.

Enteramente a la merced de tu presencia ardientemente deseada o de tu ausencia desesperadamente vivida, cuando estoy frente a ti estoy bajo tu imperio absoluto. Si estás alegre estoy alegre, si estás triste estoy triste: no tengo tiempo de pensar, sólo ${ }^{5}$ puedo sentir. Cuando te vas pienso y reflexiono y me avergüenzo de imaginar que puedes juzgarme egoísta, o aun peor, que puedes interpretar mi vehemencia como la voracidad elemental de la satisfacción de un deseo. Esto estaría muy lejos de la verdad. Mi afecto por ti es tan profundo, tan leal, tan puro que no puede tener uno sino múltiples aspectos.

Cuando te digo cosas que pueden parecerte pueriles, no hago sino exteriorizar en forma espontánea una convicción. No me explico cómo los demás no perciben inmediatamente lo que yo veo, no supongo, veo en ti. O quizá hay demasiada gente que lo ve como yo, y entonces me entristece pensar que, si bien nadie puede quererte como yo, en cambio todos tienen más méritos y mayor posibilidad de hacerse querer por ti. Cuando digo quererte hago abstracción de todo aquello que pueda

5 Transcribimos tal cual la puntuación original con el fin de no alterar el sentido original que le quiso dar el poeta surrealista César Moro. 
parecerte equívoco y queda siempre una extensión inmensa de afecto y de ternura.

Pensar que tú puedes creer que me divierto, que estoy alegre o siquiera tranquilo lejos de ti, me entristece como si hubiera cometido un crimen. Nada puede distraerme de mi única preocupación, de mi solo pensamiento, de la tristeza incurable de no verte a todas horas, de estar lejos del maravilloso espectáculo, de tu presencia. Te quiero, comprende solamente esta cosa sencilla y terrible: querer y querer cada día más y con más fuerza y hacer que el Universo dependa de tu voluntad o de tu capricho. El tiempo es hermoso si tú quieres, horriblemente triste si estás triste o si tu rostro se cubre con las nubes de la cólera o del disgusto. Apenas te alejas y ya el cielo radioso se oscurece.

Domingo, 23 de octubre [de 1938]

\section{B. Despliegue mítico e ilusión del significante Amo}

En el primer párrafo de este poema encontramos el despliegue del «discurso del Amo»; los elementos que integran este engranaje significacional empiezan su labor de recorrido y fascinación: «Un deseo de verdadera comunicación contigo se hace más y más urgente» (Moro, 2016, p. 339). Recordemos que en el $S_{2}$, lugar donde se posiciona el Esclavo, el amante, erastés, se descubre la batería de significantes que alumbran e incitan el desplazamiento mítico, imaginario, del significante Amo, $\mathrm{S}_{1}$, quien representa a un sujeto, $\mathrm{S}$, el amado, erómenos. Desde la posición del $\mathrm{S}_{2}$ irradia un «deseo verdadero de comunicación» (p. 339), pues tanto el deseo como la verdad, allende de la comunicación (conocimiento), provienen desde este lado, puesto que el Esclavo es quien tiene dicho saber, por ello, el $\mathrm{S}_{1}$ se halla ilusionado ante la posibilidad de conocer esa sapiencia.

Esta ilusión del significante Amo se debe al fantasme inicial generado desde el frente del otro significante con la finalidad de que principie su recorrido y se conjeture el sistema de subordinación. Lo que sucede entre el Amo no barrado (S) - representado por $\mathrm{S}_{1}$ - y el Esclavo es que no hay una relación por causa de los emplazamientos en los que se sitian, como se grafica también en el poema: «A veces me parece que no somos bastante amigos, que tienes muchas reservas conmigo» (p. 339). Por supuesto, sobre la correlación de dominación del Amo no dividido, amado, y el Esclavo, amante, no existe dicha amistad, pues este último cumplirá luego una función laboral de explotación y de manutención del Amo verdadero. El distanciamiento amical que hay entre ambos actuantes provoca «muchas reservas», verbigracia, el saber apartado que tiene el erastés en concordancia con el erómenos, quien se encuentra encandilado y con curiosidad por tener, robar, aquel discernimiento, puesto que el Amo no 
sabe, pero desea ello. Efectivamente, recordemos que el sujeto, quien es representado por un $\mathrm{S}_{1}$, es en potencia un Amo porque no sabe cómo se desplegará el sistema, tampoco mantenerlo. La no-relación entre ambos, al parecer, se debe a un origen desconocido, como se enuncia en el texto: «Quizá yo, sin quererlo, tenga la culpa» (p. 339). Esta afirmación es correlativa con lo dicho: el Amo, el erómenos, no tiene el mayor grado de conocimiento de esta estructura, pues quien sí sabe es el Esclavo, el erastés, por lo que suscita la partida imaginaria del $\mathrm{S}_{1}$ al comienzo del texto debido a la fabricación del fantasma que hace posible la relación primitiva, aunque engañosa, del «discurso del Amo».

\section{Identificaciones especulares y el objet petit a}

En el texto, el sujeto se encuentra a disposición del Esclavo, el amante, eje del sistema que encumbrará aquel como Amo tal cual: «Enteramente a la merced de tu presencia ardientemente deseada o de tu ausencia desesperadamente vivida, cuando estoy frente a ti estoy bajo tu imperio absoluto» (p. 339). Lo que se desprende de la cita es la confirmación de una de las implicancias que se diserta en nuestra hipótesis general, el «discurso del Amo», donde el Esclavo es quien esclaviza al Amo, pues este depende del primero, ya que al no existir el amante, no habría un sistema de subordinación ni amado. De este modo, se comprende la prédica apologética del Emisor, $\mathrm{S}_{1}$, que representa al erómenos, hacia el receptor, $\mathrm{S}_{2}$, erastés, donde se le describe a este con una omnipresencia imperante. A partir de aquí, la fascinación irradiada desde el $\mathrm{S}_{2}$ debido a la batería de significantes del Otro, quien se coloca en este lugar, principia a cumplir su finalidad: servir como elementos formadores y de identificación para el $\mathrm{S}$ no escindido representado por el $\mathrm{S}_{1}$ : «Si estás alegre estoy alegre, si estás triste estoy triste: no tengo tiempo de pensar, solo puedo sentir (p. 339)». Estas identificaciones se deben a la teoría del espejo, donde el sujeto empieza a tomar y discriminar ciertos elementos situados en el plano de lo Imaginario que le permiten constituirse como \$ castrado. Justamente, a causa de estos objetos imaginarios es que se inicia el recorrido mítico, imaginario, de $S_{1}$. La cita, además, nos delinea la plena formación del Amo dividido, $\$$, por ello, no puede pensar, razonar, dado que no ha adquirido el lenguaje que lo tachará. El amado aún siente, no discierne, ya que se muestra como un Amo no dividido, inestable, imaginado; por este motivo, su caracterización colinda con lo dinámico, vehemente, radical, puesto que aún no ha sido desubjetivado: «Cuando te vas pienso y reflexiono y me avergüenzo de imaginar que puedes juzgarme egoísta, o aun peor, que puedes interpretar mi vehemencia como la voracidad elemental de la satisfacción de un deseo» (p. 339; la cursiva es nuestra). Lo que notamos es que con la huida del Esclavo, el Amo se castra y por momentos deja de estar ciego, ya 
que puede visualizar su comportamiento indomable, su ser violento y fogoso relacionado con el deseo, el objeto-causa de deseo que anhela pero que nunca encuentra, pues siempre es huidizo de satisfacer. Esto lo deshonra, avergüenza, ya que eso, su actitud virulenta por el deseo, está en lo más íntimo de él y que es en él más que él mismo, el objet petit $a$. Empero, este cuerpo íntimo, aunque ajeno a la vez, está sumamente enraizado en \$; no obstante, eso es inubicable pues adopta una diversidad de rostros en la misma interioridad del Amo: «Esto estaría muy lejos de la verdad. Mi afecto por ti es $\tan$ profundo, $\tan$ leal, $\tan$ puro que no puede tener uno sino múltiples aspectos» (p. 339; la cursiva es nuestra). El objeto $a$ se encuentra en estado puro porque proviene del inconsciente («profundo»), por tanto, su naturaleza es violencia genésica, deseo flotante que trastoca la realidad, por lo que existe la obligación de perderlo.

\section{El Amo está ciego}

En el «discurso del Amo», luego de la partida primitiva del $\mathrm{S}_{1}$ y el proceso de identificación con los objetos formadores, el Amo se ciega, puesto que no hay un fantasme, una realidad que cubra la relación directa del sujeto desubjetivado, $\$$, con el objeto-causa de deseo, el $a$. En el texto, la castración se ha manifestado cuando el Esclavo, el amante, se va, pues empieza a dilucidar su estado anterior, el Imaginario, donde no había control ni reglas. Ahora el sujeto barrado habla ${ }^{6}$, se descubre escindido de lo que era íntimo a él, el objet petit $a$; no obstante, este elemento reprimido será perpetuamente anhelado. Con ello, se establece una relación inestable, una conexión que no puede establecerse, por lo que el Amo prefiere cegarse ante la inexistencia del fantasma que haría posible esta correspondencia: «Cuando te digo cosas que puede parecerte pueriles, no hago sino exteriorizar en forma espontánea una convicción. No me explico como los demás no perciben inmediatamente todo lo que yo veo, no supongo, veo en ti» (p. 339; la cursivas es nuestra). El Amo castrado no percibe ni logra entender por qué él si puede visualizar en el Esclavo algo que lo encandila a diferencia de otros que no denotan nada especial. Hay en él un objeto que el amado anhela y que ha perdido en el momento de hablar y que lo ha descolocado del Imaginario; empero, no sabe qué cosa es. Asimismo, el Amo no ve lo que es real, el Esclavo, ya que desde la posición del $\mathrm{S}_{2}$ se desprende el objeto a que es imposible de retener; entonces, el Esclavo situado aquí es por supuesto real, el caos primitivo del cual emerge el sujeto, $\mathrm{S}$.

6 Recordemos que la voz pertenece a uno de los elementos en los que se puede manifestar el objeto $a$, ya que es un resto del proceso de desubjetivación. 
Al encontrarse ciego y no ver la conexión que haría imposible, real, su relación, el Emisor cuestiona el proceder tanto de él como del Esclavo: «O quizá haya demasiada gente que lo ve como yo, y entonces me entristece pensar que, si bien nadie puede quererte como yo, en cambio todos tienen más méritos y mayor posibilidad de hacerse querer por ti» (pp. 339-340). Esta actitud se debe a que el amante, el Esclavo, tiene el saber que todos quieren y que este dispone para el Amo de turno, por ende, el lamento del erómenos, el Amo, el \$, debido a que el Esclavo no irradia su presencia exclusivamente para aquel. Nuevamente encontramos una de las consecuencias del "discurso del Amo» ya referenciadas, en el cual el Amo es realmente un subyugado del Esclavo, pues está sometido a las disposiciones de este: «Cuando digo quererte hago abstracción de todo aquello que pueda parecerte equívoco y queda siempre una extensión inmensa de afecto y de ternura» (p. 340; la cursiva es nuestra). Con la cita, se colige la dependencia existente y encadenada del erómenos hacia el erastés, ya que al eliminar su «equívoco», el objeto $a$, lo que ha desechado para encumbrarse como Amo, solo queda el «afecto», es decir, lo que lo hace que se encuentre «[i]nclinado a alguien o algo» (Real Academia Española, 2014).

\section{E. El Amo castrado que lo arriesga todo}

El Amo se encuentra castrado. El barrado de su subjetividad se ha debido a las identificaciones formadoras que se desplegaron en el plano de lo Imaginario por la irradiación que estas hicieron para que el Significante Amo empiece su desplazamiento y represente al sujeto, amado, erómenos, ante otro significante, el $\mathrm{S}_{2}$, el Esclavo, el erastés. En el texto poético la división del Amo no tachado se manifestó cuando el Esclavo se fue, con lo que dejó a aquel su juego imaginario de violencia y desmesura; a causa de ello, el reclamo y la reiteración del Amo ahora ya clivado: «Pensar que tú puedes creer que me divierto, que estoy alegre o siquiera tranquilo lejos de ti, me entristece como si hubiera cometido un crimen» (p. 340). El sujeto antes gozaba en diversión, pero al ser barrado y convertirse en Amo (\$) por la lejanía del Esclavo, se muestra triste, sin alegría, puesto que ya se posiciona en lo simbólico, donde están los símbolos, el lenguaje, el raciocinio, que lo han desubjetivado: «Nada puede distraerme de mi única preocupación, de mi solo ${ }^{7}$ pensamiento, de la tristeza incurable de no verte a todas horas, de estar lejos del maravilloso espectáculo de tu presencia» (p. 340; la cursiva es nuestra). Hay una nostalgia de lo desechado, excluido, el objet petit $a$, que el Amo tuvo que restarse cuando el Esclavo, el amante, principió a irse de su lado. Lamentablemente, la ausencia del Esclavo, el

7 La construcción sintáctica es del original. 
erastés, pese a la castración del Amo, permanece latente, anhelante, aunque jamás ubicado, por su naturaleza correlativa con el objeto $a$.

El deseo del emisor hacia el receptor se deja sentir al final del texto; este deseo lo atormentará, pues se ha metaforizado y adscrito al amante, el Esclavo: «te quiero, comprende solamente esa cosa sencilla y terrible: querer y querer cada día más y con más fuerza y hacer que el universo dependa de tu voluntad o de tu capricho» (p. 340). Según el Diccionario de la lengua española (2014), «querer» es «1. Desear o apetecer». Por consiguiente, si el querer, el deseo, se halla en el erastés, se puede colegir que lo ambicionado se muestra ausente, lejano, pues el Esclavo se encuentra desaparecido; con ello, terminamos de confirmar la sustancia misma del objeto-causa de deseo, siempre desviado, que motiva la búsqueda, lamento y deseo del Amo por aquel objet $a$, el Esclavo. Entonces, se puede inferir el poder que tiene el erastés, ya que genera todo este deseo y angustia del Amo; incluso, generar que el Universo dependa de él. Recordemos que el Esclavo es quien tiene el saber a causa de la verdad que él conlleva en su labor; empero, la subordinación del amado ante el amante provocará un riesgo, ya que este es real, caótico: «El tiempo es hermoso si tú quieres, horriblemente triste si estás triste o si tu rostro se cubre con las nubes de la cólera o del disgusto» (p. 340). Los objetos imaginarios que sirvieron en la formación del Amo, \$, se muestran latentes en el Esclavo, ya que él se halla en $\mathrm{S}_{2}$ donde existe el tesoro de significantes del Otro. Por ello, la función del Esclavo, el amante, es trascendental en la configuración del mundo simbólico del Amo por lo que su extinción, el instinto de muerte, acabaría con todo el «discurso del Amo», puesto que ya no habría persona alguna que laboraría para la manutención del sujeto barrado como Amo verdadero. En consecuencia, se infiere que el alejamiento, la desaparición del Esclavo, el erastés, destruiría el sistema de subordinación: «Apenas te alejas y ya el cielo radioso se oscurece» (p. 340). La omnipotencia del amante deja su huella en esta cita, pues el cielo, el límite de lo máximo, se torna sombrío; es decir, el Esclavo es mucho más poderoso que el mismo sol que alumbra la vida. En síntesis, por la no-relación que se escribe entre el Amo y el Esclavo, el «discurso del Amo» se vuelve inestable, imposible de hacer, ya que es real. Ahora bien, pese a que el Emisor trata de establecer ciertas correspondencias, la imposibilidad del sistema, la desconexión entre el amado y el amante, el erómenos y el erastés, el Amo y el Esclavo, se evidencia de principio a fin en el texto, puesto que todo es real.

\section{F. Esquema del "discurso del Amo» en la carta "l»}

A lo largo del poema el emisor, el significante Amo, ha emprendido su desplazamiento imaginario por la irradiación de los objetos formadores, que se sitúan en $\mathrm{S}_{2}$, donde se halla el Esclavo, el amante, el erastés. Este 
deja sentir su omnipotencia frente al Amo aún no escindido y que es representado por $\mathrm{S} 1$ ante aquel. Las identificaciones principian por parte del locutor poético hasta que el Amo no barrado habla; acción que evidencia la castración, exclusión del objet petit $a$, como consecuencia de la partida del Esclavo. La lejanía de este ha provocado el ascenso del \$, el erómenos, al mundo de lo Simbólico, el referente en el que dictaminan los símbolos; con esto, el Amo, recuerda su estancia imaginaria donde ha existido vehemencia y convivencia entre el amado y el amante. Por ello, el Esclavo es visto como deseo que huye, nunca alcanzado, por su idiosincrasia de objet petit a. La distancia de este, debido a su poder presente, genera zozobra en el «discurso del Amo»; por tanto, al presentarse ausente, el sistema de subordinación que somete al $\mathrm{S}_{2}$ se aniquila totalmente. Así, la estructura de sojuzgamiento y mecanismos de subyugación hacia el Esclavo se torna imposible de mantenerse, ya que el conjunto sistemático, así como sus factores, pertenecen a lo real. Por lo expuesto, el esquema del poema analizado quedaría del siguiente modo:

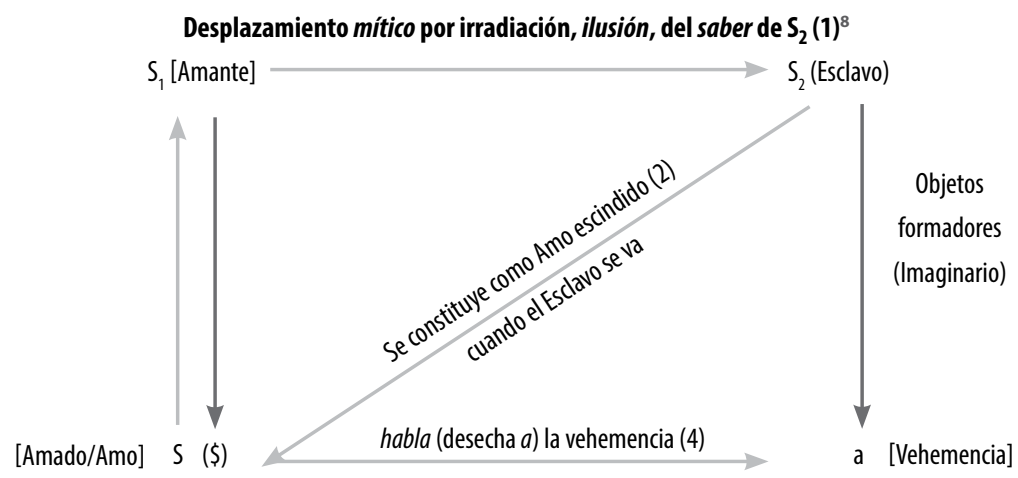

No hay fantasma, pero el Amo está ciego ante lo real

(hay imposibilidad de relación)

El sistema es real

\section{Conclusiones}

Como se ha visto a lo largo del presente artículo, la poesía de Cesar Moro ha sufrido de obstáculos para una aproximación exegética adecuada debido al idioma francés en el cual se encuentra escrito casi la totalidad de su obra, el lenguaje surrealista, y el tópico de amor uranista. A causa de estos inconvenientes, se ha obviado otros textos como las Cartas a Antonio, proyecto poético que solo ha sido estudiado tangencialmente o en relación a otros libros publicados del bardo peruano.

8 La enumeración indica la cronología del «discurso del Amo». 
De otro lado, en esta circular lírica lo que se ha encontrado es la disposición del «discurso del Amo», en el cual se establece una relación de poder y subordinación entre dos actuantes, el Amo y el Esclavo, que funciona como mecanismo poético de dicha estructura. Así, este proceso se imbrica con el desarrollo de la cadena significante y el sistema significacional de la castración, en el cual el sujeto se ilusiona ante la irradiación de los objetos identificatorios que provocan el desplazamiento del Significante Amo, que representa a un sujeto ante otro significante, hacia el $\mathrm{S}_{2}$, donde se sitúa el Esclavo, el saber y el Otro, que está constituido con la batería de significantes que ilusionan al $\mathrm{S}_{1}$. En este procedimiento, el sujeto discrimina ciertos elementos constituyentes ubicados "más allá» del espejo. Luego, el $\mathrm{S}$ se posiciona en el imaginario en el que vive una utopía con su deseo. Por último, aquí se le transfiere el instinto de muerte que lo expulsa de este mundo imaginario hacia lo simbólico en el cual se sitúa castrado.

Asimismo, lo dicho nos permite relacionar el proceso de significación con el «discurso del Amo», puesto que el $\mathrm{S}$ se ilusiona ante la presencia del Esclavo, quien posee el saber que desea el Amo para constituirse como \$. A partir de ello, se producirá una serie de consecuencias por motivo de este desplazamiento inicial: la ilusión del Amo, el Amo no sabe que es \$ pero desea, el Amo roba el saber del Esclavo, la teoría del espejo, el Amo está ciego, y el Amo arriesga todo (el instinto de muerte). También, se establece los interlocutores, en el que el amado, erómenos, es el emisor, el Amo, así como el amante, erastés, es el receptor, el Esclavo, ya que la exhortación enunciada dispone una serie de características propias del amado, tal cual la apología del otro, la destrucción del referente por la ausencia del amante, la transgresión, etc.

Para finalizar, en la epístola «l: Domingo, 23 de octubre [de 1938]», que corresponde al conjunto textual de las Cartas a Antonio, se demuestra la existencia del «discurso del Amo» como eje funcional de su estructura poética. Aquí el Amo, el amado, se desplaza mediante un Significante Amo, hacia el Esclavo, debido a la ilusión que ha despertado el amante por sus características y sabiduría que irradia frente al sujeto. Luego, se observó una identificación con el amante, pues este porta un esplendor inigualable. Después, el Amo no barrado se mostró ciego ante su relación directa con su objeto-causa de deseo, el Esclavo, ya que no existe un fantasme que inhiba esta correlación. Sin embargo, esta misma situación hará que arriesgue todo, pues el erastés ya está ausente, perdido, por lo que avizora una destrucción del referente por no asir a su objet petit $a$; por este motivo, el sistema se vuelve real, imposible, de sostener y generar. 
Con ello, se ha tratado de brindar una perspectiva diferente a los estudios realizados a las Cartas a Antonio no solo de manera metodológica, sino a nivel teórico, ya que se ha podido establecer cuál es el mecanismo poético que hace funcionar el discurso amoroso del Emisor en la correspondencia lirica escrita en una etapa muy fructífera de César Moro, como es el periodo mexicano (1938-1948) y el denominado «ciclo de Antonio». 


\section{REFERENCIAS BIBLIOGRÁFICAS}

LACAN, J. (1985). El seminario 20. Aún. Barcelona: Paidós.

nos Aires: Paidós.

(1996). El Seminario 17. El reverso del psicoanálisis. Bue-

(1997). El Seminario 7. La ética del psicoanálisis. Buenos

Aires: Paidós.

(1998). El Seminario 1. Los Escritos Técnicos de Freud. Buenos Aires: Paidós.

(2003). El Seminario 8. La transferencia. Buenos Aires:

Paidós.

(2008). El Seminario 16. De un Otro al otro. Buenos Ai-

res: Paidós.

MORO, C. (2002). Prestigio del amor. Selección, traducción y prólogo de Ricardo Silva-Santisteban. Lima: Fondo Editorial de la Pontificia Universidad Católica del Perú.

(1998). Prestigio del amor. Selección, traducción y prólogo de Ricardo Silva-Santisteban. Obras esenciales 1. Lima: Fondo Editorial de la Pontificia Universidad Católica del Perú.

PACHECO QUISPE, J. (2014). La metáfora del amor en La tortuga ecuestre de César Moro (tesis de licenciatura inédita). Universidad Nacional Mayor de San Marcos, Lima.

Real Academia de la Lengua Española (2014). Diccionario de la lengua española. Madrid: Real Academia de la Lengua Española.

Recibido: enero de 2017

Aprobado: marzo de 2017 